\title{
Effects of process parameters on morphology and distribution of externally solidified crystals in microstructure of magnesium alloy die castings
}

\author{
Meng-wu Wu, ${ }^{1,2}$, Xiao-bo $\mathbf{L i}^{2}$, Zhi-peng Guo ${ }^{2}$ and *Shou-mei Xiong ${ }^{2}$ \\ 1. Hubei Key Laboratory of Advanced Technology for Automotive Components, Wuhan University of Technology, Wuhan 430070, China; \\ 2. School of Materials Science and Engineering, Tsinghua University, Beijing 100084, China
}

\begin{abstract}
During the cold-chamber high pressure die casting (HPDC) process, samples were produced to investigate the microstructure characteristics of AM60B magnesium alloy. Special attention was paid to the effects of process parameters on the morphology and distribution of externally solidified crystals (ESCs) in the microstructure of magnesium alloy die castings, such as slow shot phase plunger velocity, delay time of pouring and fast shot phase plunger velocity. On the basis of metallographic observation and quantitative statistics, it is concluded that a lower slow shot phase plunger velocity and a longer delay time of pouring both lead to an increment of the size and percentage of the ESCs, due to the fact that a longer holding time of the melt in the shot sleeve will cause a more severe loss of the superheat. The impingement of the melt flow on the ESCs is more intensive with a higher fast shot phase plunger velocity, in such case the ESCs reveal a more granular and roundish morphology and are dispersed throughout the cross section of the castings. Based on analysis of the filling and solidification processes of the melt during the HPDC process, reasonable explanations were proposed in terms of the nucleation, growth, remelting and fragmentation of the ESCs to interpret the effects of process parameters on the morphology and distribution of the ESCs in the microstructure of magnesium alloy die castings.
\end{abstract}

Key words: magnesium alloy; high pressure die casting; microstructure; externally solidified crystals; process parameters

CLC numbers: TP/391.99/TG146.22 Document code: A Article ID: 1672-6421(2018 02-139-06

\begin{abstract}
A $\mathrm{s}$ the lightest known structural metals, magnesium alloys have attracted much attention due to their superior properties such as low density, high specific strength, excellent castability, good machinability and recyclability ${ }^{[1-3]}$. Magnesium alloys have been widely used in automotive, aerospace and 3C (computer, communication and consumer electronics) industries to replace steel, cast iron and even aluminum alloys ${ }^{[4-6]}$. The high pressure die casting (HPDC) process is a netshape or near net-shape process with the advantages of high efficiency, considerable economic benefit, and high precision of the product size ${ }^{[7,8]}$. These remarkable advantages make the HPDC process particularly suitable for various complex castings' production with
\end{abstract}

\section{*Shou-mei Xiong}

Male, born in 1966, Ph.D., Professor. Research interests: advanced manufacturing processes and technologies for magnesium and aluminum alloys.

E-mail: smxiong@tsinghua.edu.cn

Received: 2017-12-03; Accepted: 2018-02-05 magnesium alloys, and generally, magnesium alloy parts are mainly formed by the HPDC process ${ }^{[9,10]}$.

During the cold-chamber HPDC process, the molten melt at a certain temperature enters into the shot sleeve through a quantitative pouring unit. After the slow shot and fast shot phases, the liquid melt fills the die cavity with a high speed and pressure. Finally, the die cast component is formed with a certain shape after a short solidification time. In recent years, Laukli et al. ${ }^{[11,12]}$ and Cao et al. ${ }^{[13]}$ have proposed a theory regarding the coldchamber HPDC process, in which they considered that when the melt was kept in the shot sleeve, especially at the slow shot phase, the melt's superheat was lost due to the impingement on the relatively cold shot sleeve wall and plunger. In this case, nucleation and crystal growth occurred in the melt in the shot sleeve. At the fast shot phase, a mixture of liquid and crystals was injected into the die cavity, and during this phase, the floating crystals migrated to the central region of the die cavity due to the force of the flowing melt. Accordingly, the pre-solidified crystals in the shot sleeve, which were named "Externally Solidified Crystals (ESCs)", had a 
significant influence on the final microstructure and performance of die castings.

During the practical cold-chamber HPDC process, owing to the constraining relationship among the process parameters, complete avoidance of the ESCs in the microstructure of die castings seems impossible, while the percentage of the ESCs may possibly be reduced by optimizing the process parameters. Though several studies have been reported on the formation of the ESCs in die castings ${ }^{[11-19]}$, there is still a lack of systematic and quantitative research on the effects of process parameters on the morphology and distribution of ESCs in the microstructure of die castings.

In the present study, die cast samples with AM60B magnesium alloy were produced using different process parameters (such as slow shot phase plunger velocity, delay time of pouring and fast shot phase plunger velocity, etc.). Metallographic observation and quantitative statistics were conducted to investigate the effects of process parameters on the morphology and distribution of the ESCs in the microstructure of die castings. Moreover, the effect mechanism was also discussed in detail in terms of the nucleation, growth, remelting and fragmentation of the ESCs on the basis of the analysis of the filling and solidification processes of the melt during the HPDC process.

\section{Experimental procedure}

Commercial AM60B magnesium alloy was used in the die casting experiment. According to the analysis of ICP (Inductively Coupled Plasma), its composition is listed in Table 1, and the liquidus and solidus temperatures are $888 \mathrm{~K}$ and $813 \mathrm{~K}$, respectively. Figure 1 illustrates the schematic diagram of the die cast sample, which includes three tensile test bars and one sample piece. The diameter at the center of each tensile test bar is $6.4 \mathrm{~mm}$, while the thickness of the sample piece is $2.5 \mathrm{~mm}$. The die casting experiment was conducted on a TOYO BD350V5 cold-chamber HPDC machine under a vacuum degree of $6.9 \mathrm{kPa}$, while the standard process parameters were as follows: pouring temperature $(953 \mathrm{~K})$, mould temperature $(453 \mathrm{~K})$, casting pressure $(87 \mathrm{MPa})$, slow shot phase plunger velocity $(0.2$ $\left.\mathrm{m} \cdot \mathrm{s}^{-1}\right)$, delay time of pouring $(2.5 \mathrm{~s})$, and fast shot phase plunger velocity $\left(2.0 \mathrm{~m} \cdot \mathrm{s}^{-1}\right)$. Particularly, three groups of die cast samples with different slow shot phase plunger velocities $(0.1,0.2,0.3$ and $\left.0.4 \mathrm{~m} \cdot \mathrm{s}^{-1}\right)$, delay time of pouring $(2.5,3.5,4.5$ and $5.5 \mathrm{~s})$ and fast shot phase plunger velocities $\left(2.0,2.5,3.0\right.$ and $\left.4.0 \mathrm{~m} \cdot \mathrm{s}^{-1}\right)$ were produced to investigate the effects of process parameters on the microstructure of the die castings.

Metallography observation was carried out by using OM (optical microscopy), SEM (scanning electron microscopy) and EBSD (electron back-scattered diffraction). The metallographic

Table 1: Chemical composition of AM60B magnesium alloy used in the experiment (wt.\%)

\begin{tabular}{ccccccc} 
Al & Mn & Zn & Si & Cu & Fe & Mg \\
\hline 5.90 & 0.31 & 0.16 & 0.06 & 0.007 & 0.003 & Bal.
\end{tabular}

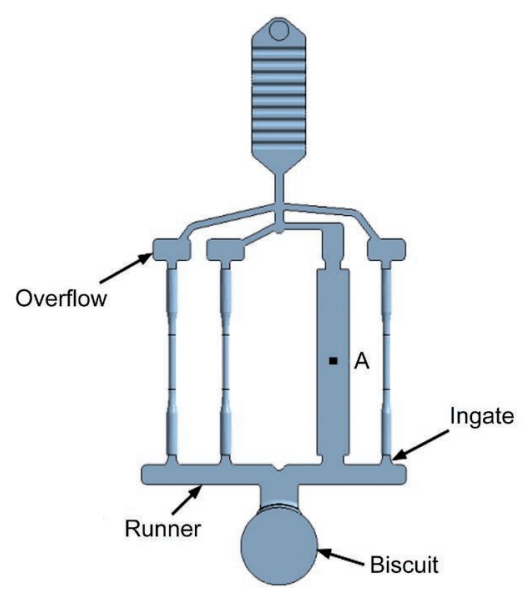

Fig. 1: Schematic diagram of die cast sample with investigated through thickness cross section designated as $\mathrm{A}$

pieces were taken from location A as shown in Fig. 1. After being mechanically ground and polished, the metallographic pieces were etched with an etching solution of $4.2 \mathrm{~g}$ picric acid, $70 \mathrm{~mL}$ ethanol, $10 \mathrm{~mL}$ acetic acid, and $10 \mathrm{~mL}$ distilled water for $\mathrm{OM}$ observation. Another etching solution of $75 \mathrm{~mL}$ glycol, $24 \mathrm{~mL}$ distilled water, and $1 \mathrm{~mL}$ nitric acid was also used for SEM observation and analysis. Specimens for EBSD were prepared by conventional mechanical polishing followed by electrochemical polishing. The polishing solution was commercial AC-2 electrolyte, while the polishing time was about $30-60 \mathrm{~s}$.

According to the grain size and pixel color, an image analysis software MIAPS (micro-image analysis \& process system) was adopted to recognize and distinguish the ESCs from the bulk structure shown in the metallographs. Consequently, quantitative statistics of the percentage of the ESCs were conducted. In this study, based on the measurement and statistics of the grain size of die cast AM60B magnesium alloy, a critical grain size of 10 $\mu \mathrm{m}$ was selected so that those crystals with a grain size larger than this value were identified as ESCs. During the quantitative analysis of the percentage of the ESCs, two variables, $d$ and $f_{\mathrm{ESCs}}$, were defined and given as follows:

$$
\begin{aligned}
d & =2 \sqrt{A_{i} / \pi} \\
f_{\mathrm{ESCs}} & =\sum_{i=1}^{n} A_{i} / A_{0}
\end{aligned}
$$

where $d$ and $A_{i}$ denote the diameter and area of a single ESC (Externally Solidified Crystal), respectively. $f_{\mathrm{ESCs}}$ is the area fraction of the ESCs, and $A_{0}$ represents the total area of the statistical zone.

\section{Results and discussion}

\subsection{Microstructure characteristics of ESCs}

The final microstructure of castings with cold-chamber HPDC process is not the same as the commonly observed microstructure of castings with conventional casting processes. 
Figure 2 shows the typical microstructure of AM60B magnesium alloy at the central region of die cast samples by using OM, EBSD and SEM, respectively. It can be seen that the central region comprises a mixture of coarse dendrites and fine grains. The size of the basal fine grains is about $5-10 \mu \mathrm{m}$, while the equivalent grain size of the coarse dendrites is up to $100 \mu \mathrm{m}$. According to the functional relationship proposed by Sequeira et al. relating the grain size and cooling rate during solidification $^{[20]}$, the coarse dendrites should not nucleate and grow in the melt in the die cavity, since the melt solidifies with an extremely high cooling rate and a short solidification time in the die cavity. This could also help to validate the theory that the coarse dendrites in the microstructure of die castings originate from the nucleation and crystal growth in the melt in the shot sleeve.

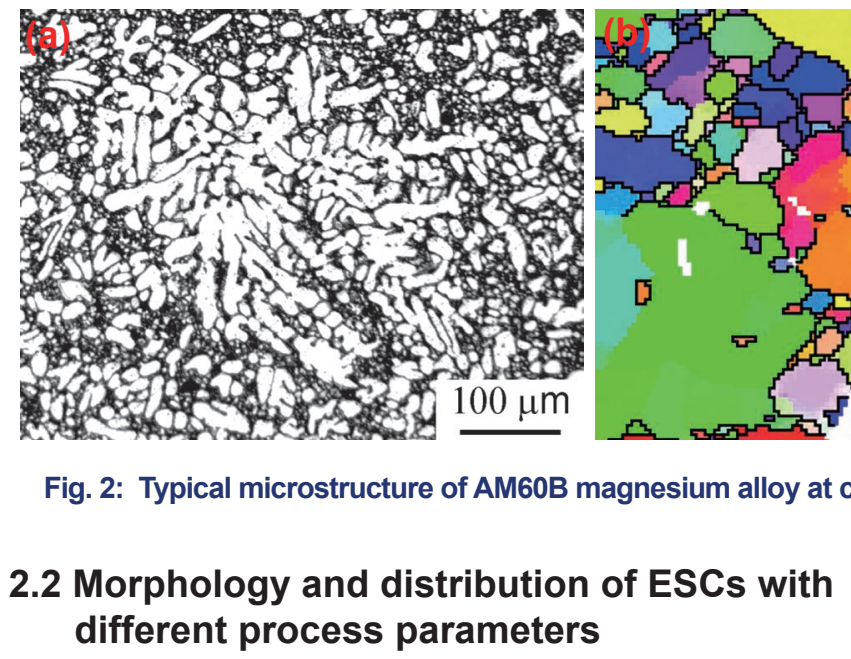

Figure 3 presents the metallographs regarding the morphology and distribution of the ESCs over a cross section of the piece samples with different slow shot phase plunger velocities and delay times of pouring. A common phenomenon can be observed firstly due to the force of the flowing melt, the ESCs migrate to the central region of the melt and finally accumulate at these corresponding areas during solidification of the die cast samples. Based on metallographic observation, the surface layer
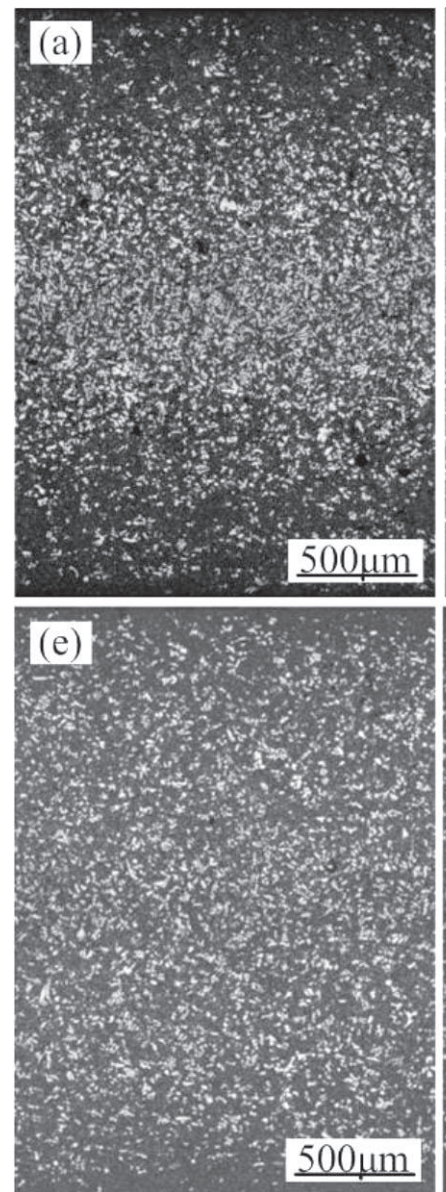
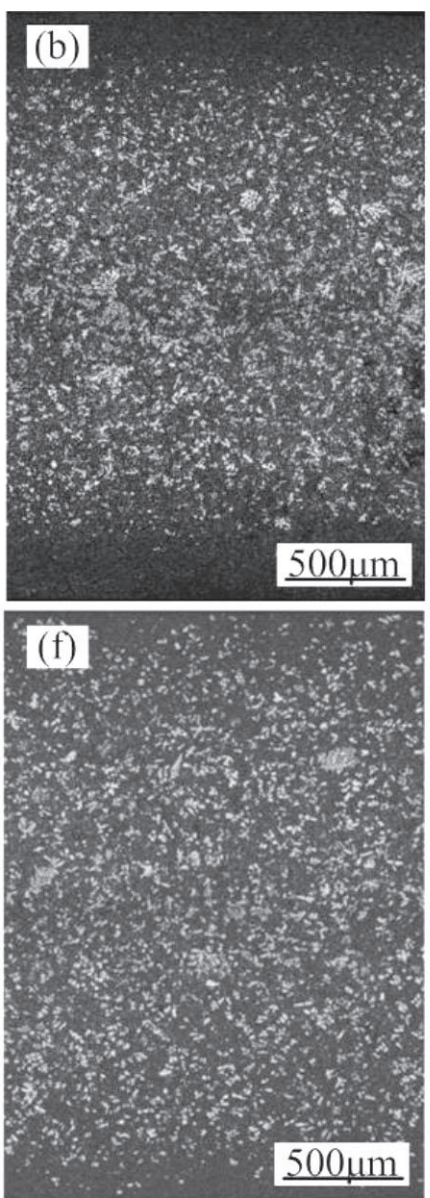
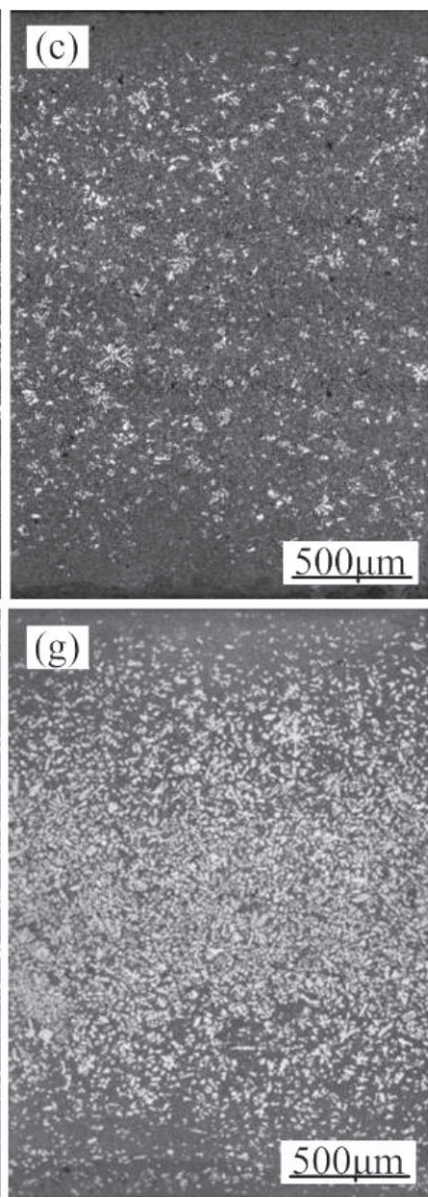
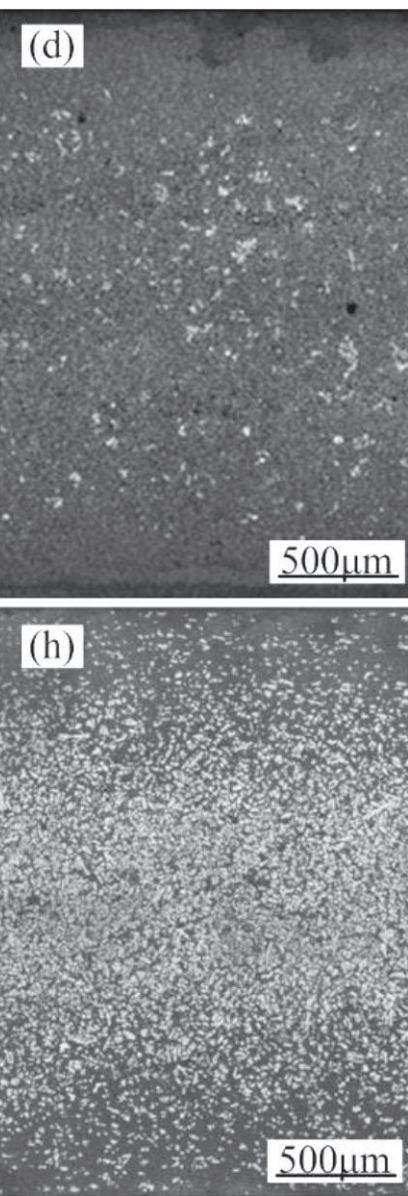

Fig. 3: Morphology and distribution of ESCs over cross section of die cast samples with different slow shot phase plunger velocities (a-d) and delay time of pouring (e-h): (a) $0.1 \mathrm{~m} \cdot \mathrm{s}^{-1}$, (b) $0.2 \mathrm{~m} \cdot \mathrm{s}^{-1}$, (c) $0.3 \mathrm{~m} \cdot \mathrm{s}^{-1}$, (d) $0.4 \mathrm{~m} \cdot \mathrm{s}^{-1}$, (e) $2.5 \mathrm{~s}$, (f) $3.5 \mathrm{~s}$, (g) $4.5 \mathrm{~s}$, (h) $5.5 \mathrm{~s}$ 
of the die cast samples consists of uniformly fine grains, while the central region contains a mixture of coarse dendrites and fine grains. Comparing the metallographs of die cast AM60B magnesium alloy with different slow shot phase plunger velocities (Figs. 3a-d), it can be noted that when the slow shot phase plunger velocity increases, the size and percentage of the ESCs decreases, and the morphology becomes more roundish and granular. As illustrated in Figs. 3e-h, a conclusion can be made that an increase of the delay time of pouring leads to a higher percentage of the ESCs, as well as a larger size of the ESCs. Moreover, since the percentage of the ESCs increases, the tendency of accumulation of the ESCs is more obvious at the central region of the die cast samples.

Figure 4 shows the morphology and distribution of the
ESCs over the cross section and at the central region of the die cast samples with different fast shot phase plunger velocities. Different from the above two process parameters, a change of the fast shot phase plunger velocity does not seem to remarkably affect the percentage of the ESCs. However, the ESCs are more dispersed throughout the cross section of the samples with increasing the fast shot phase plunger velocity. By careful observation and comparison of the amplified view of microstructure at the central region of the die cast samples (Figs. $4 \mathrm{e}-\mathrm{h}$ ), it can be seen that as the fast shot phase plunger velocity increases, the ESCs in the form of relatively coarse dendrites gradually disappear, while more ESCs with a granular and roundish morphology are observed.
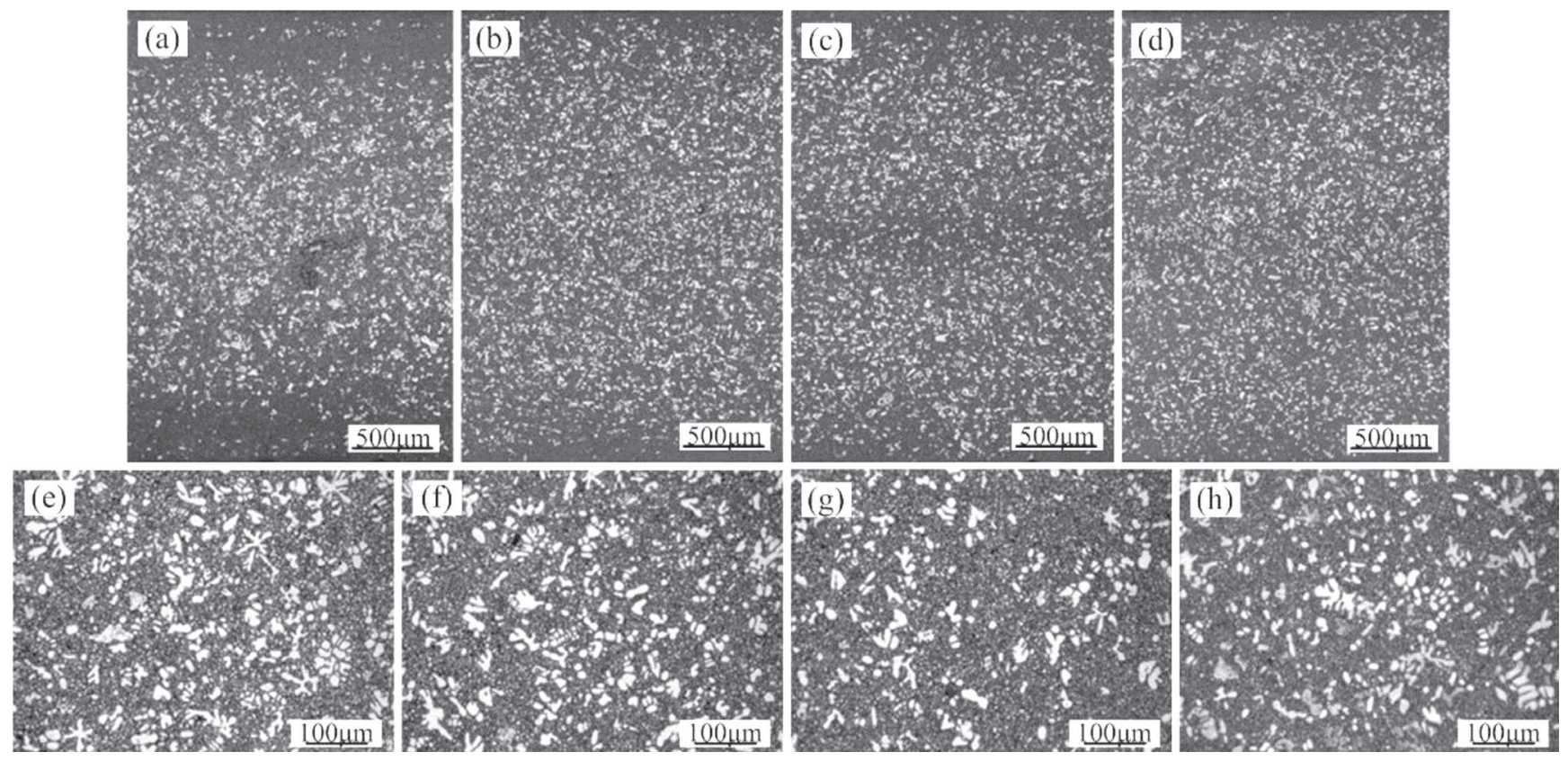

Fig. 4: Morphology and distribution of ESCs over cross section (a-d) and at the central region (e-h) of die cast samples with different fast shot phase plunger velocities $\left(\mathrm{m} \cdot \mathrm{s}^{-1}\right)$ : (a) and (e) 2.0, (b) and (f) 2.5, (c) and (g) 3.0, (d) and (h) 4.0

In order to quantitatively investigate the effects of process parameters on the morphology and distribution of the ESCs in the microstructure of die cast samples, statistics were conducted regarding the area fraction and average diameter of the ESCs. According to the statistical results as illustrated in Fig. 5, it can be noted firstly that at certain process parameters, the area fraction and average diameter of the ESCs could be up to $30 \%$ and $17 \mu \mathrm{m}$, respectively. Secondly, a conclusion can be made that the quantitative results are in accordance with the qualitative ones mentioned above, which are: the area fraction and average diameter of the ESCs both decrease to some extent with increasing the slow shot phase plunger velocity, as well as shortening the delay time of pouring; the changes of the area fraction and average diameter of the ESCs seem to be random while the fast shot phase plunger velocity increases.
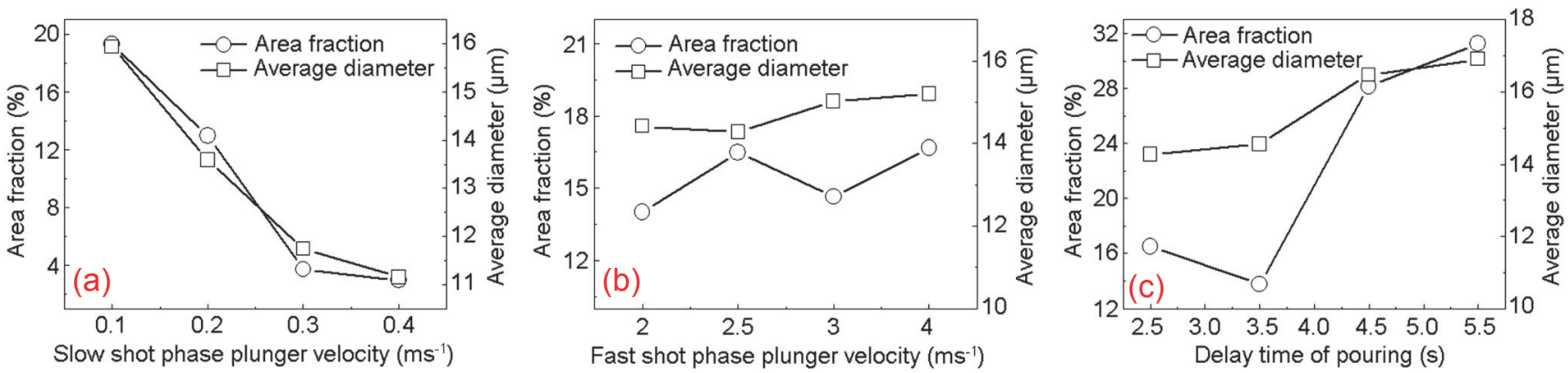

Fig. 5: Area fraction and average diameter of the ESCs with different process parameters: (a) slow shot phase plunger velocity, (b) fast shot phase plunger velocity, (c) delay time of pouring 


\subsection{Effect mechanism of the process parameters}

To gain a deeper insight into the effect mechanism of the process parameters on the morphology and distribution of the ESCs in the microstructure of magnesium alloy die castings, a detailed analysis was carried out on the filling and solidification processes of the melt during the HPDC process. As illustrated in Fig. 6(a), the microstructure evolution of the ESCs is generalized in four forms: nucleation, growth, remelting and fragmentation. At the early stage of the HPDC process when the melt is kept in the shot sleeve [Fig. 6(b)], due to the loss of the superheat of the melt, the ESCs nucleate and grow, particularly at the surface of the melt and in the melt near the shot sleeve wall. Since the slow shot phase plunger velocity is relatively low, the thermal shock and convection in the melt in the shot sleeve is extremely soft. In this case, remelting and fragmentation of the ESCs rarely happen. At the fast shot phase when the melt is in the runner, especially at the ingate [Fig. 6(c)], a high flowing speed of the melt in turbulent state leads to an intensive thermal shock and convection in the melt, which consequently results in remelting and fragmentation of the ESCs. As the time of the fast shot phase is fairly short, growth of the ESCs is quite insufficient. When the melt is in the die cavity as shown in Fig. 6(d), remelting and fragmentation of the ESCs, as well as migration of the ESCs to the central region of the die cavity happen during the filling process. The ESCs continue to grow in the die cavity during the solidification process, while massive nucleation and growth of the basal fine grains occur simultaneously in the melt.

According to the thorough description of the microstructure evolution of the ESCs during the HPDC process, effect mechanism of the process parameters on the morphology and distribution of the ESCs in the microstructure of magnesium alloy die castings can be proposed and explained then. When the slow shot phase plunger velocity increases, or the delay time of pouring is shortened, the loss of the superheat of the melt is weakened due to a less holding time of the melt in the shot sleeve. In this case, nucleation and growth of the ESCs are inhibited in the melt, which consequently leads to a lower percentage and smaller size of the ESCs in the final microstructure of die castings. As the fast shot phase plunger velocity increases, the thermal shock and convection in the melt are promoted, resulting in an acceleration of the remelting and fragmentation of the ESCs. Therefore, the ESCs reveal a more granular and roundish morphology and are dispersed throughout the cross section of the die castings.
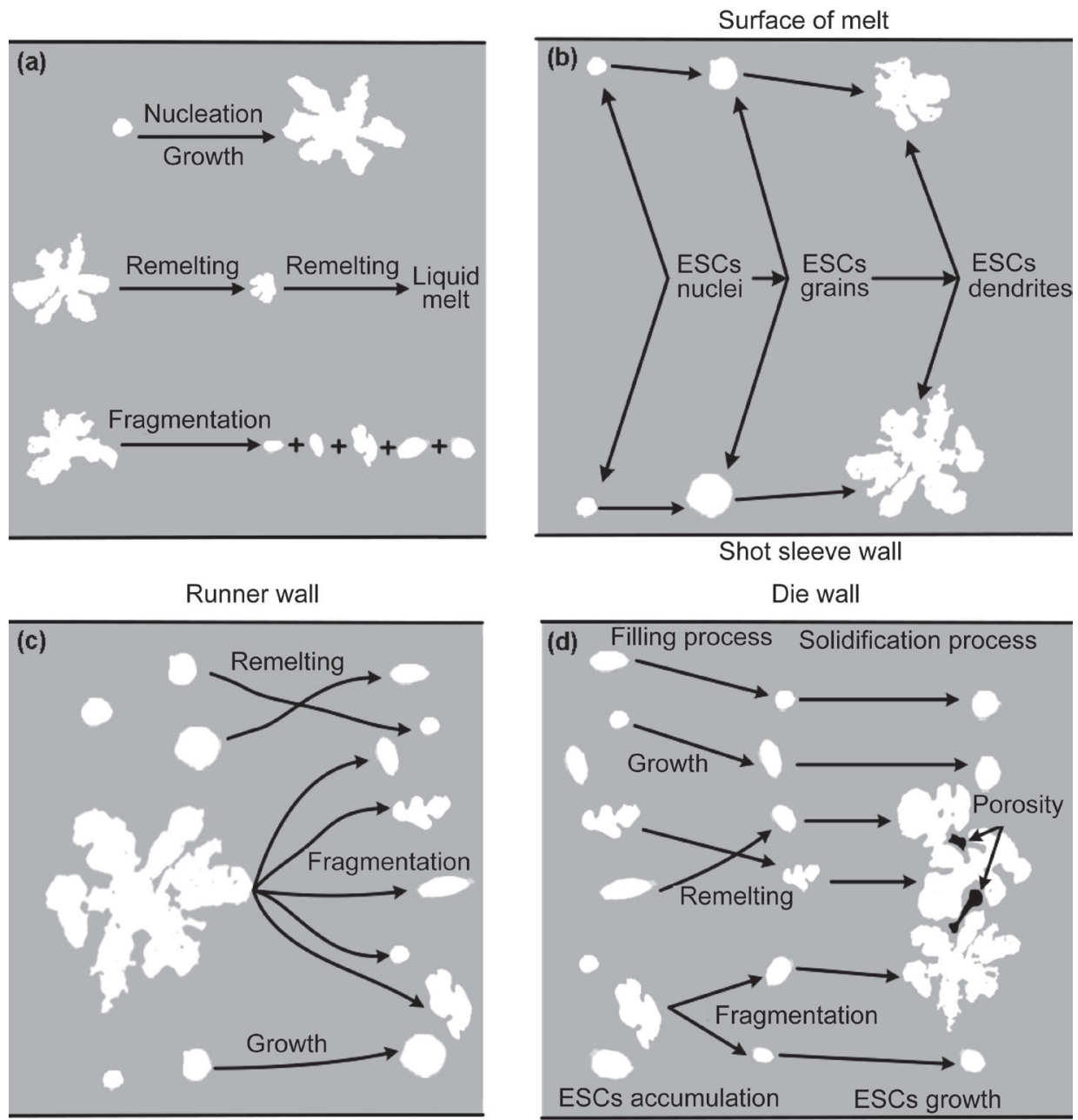

Runner wall

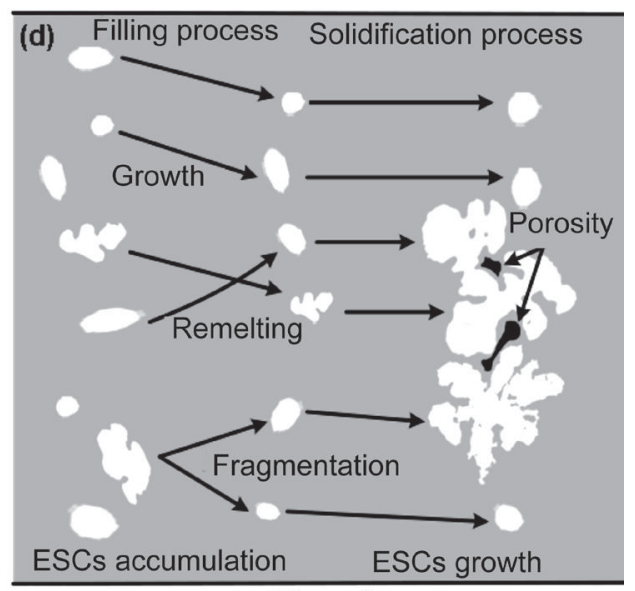

Die wall

Fig. 6: Schematic diagram of microstructure evolution of ESCs: (a) microstructure evolution of ESCs in four forms, (b) in shot sleeve, (c) in runner and at ingate, (d) in die cavity 


\section{Conclusions}

(1) The ESCs in the microstructure of magnesium alloy die castings originate from the nucleation and crystal growth in the melt in the shot sleeve. The area fraction and average diameter of the ESCs could be up to $30 \%$ and $17 \mu \mathrm{m}$, respectively.

(2) A lower slow shot phase plunger velocity and a longer delay time of pouring both lead to an increment of the size and percentage of the ESCs, due to a longer holding time of the melt in the shot sleeve which consequently promotes the nucleation and growth of the ESCs in the melt in the shot sleeve.

(3) As the fast shot phase plunger velocity increases, an acceleration of the remelting and fragmentation of the ESCs results in a more granular and roundish morphology of the ESCs. In addition, the ESCs are more dispersed throughout the cross section of the castings due to the promoted convection in the melt.

\section{References}

[1] Mordike B L, Ebert T. Magnesium properties-applicationspotential. Materials Science and Engineering A, 2001, 302(1): $37-45$.

[2] Abbott T. Why choose magnesium?. Materials Science Forum, 2009, 618-619: 3-6.

[3] Joost W J, Krajewski P E. Towards magnesium alloys for highvolume automotive applications. Scripta Materialia, 2017, 128: 107-112.

[4] Easton M A, Zhu S M, Abbott T B, et al. Evaluation of magnesium die-casting alloys for elevated temperature applications: castability. Advanced Engineering Materials, 2016, 18(6): 953-962.

[5] Zhang W, Xiao W, Wang F, et al. Development of heat resistant $\mathrm{Mg}-\mathrm{Zn}$-Al-based magnesium alloys by addition of La and Ca: microstructure and tensile properties. Journal of Alloys \& Compounds, 2016, 684: 8-14.

[6] Pekguleryuz M O, Kaya A A. Creep resistant magnesium alloys for powertrain applications. Advanced Engineering Materials, 2010, 5(12): 866-878.

[7] Yu W B, Liang S, Cao Y Y, et al. Interfacial heat transfer behavior at metal/die in finger-plated casting during high pressure die casting process. China Foundry, 2017, 14(4): 258-264

[8] Li X B, Xiong S M, Guo Z P. Failure behavior of high pressure die casting AZ91D magnesium alloy. Materials Science \& Engineering A, 2016, 672: 216-225.

[9] Li X B, Xiong S M, Guo Z P. Correlation between porosity and fracture mechanism in high pressure die casting of $A M 60 B$ alloy. Journal of Materials Science \& Technology, 2016, 32(1): 54-61.

[10] Cerri E, Leo P, Marco P P D. Hot compression behavior of the AZ91 magnesium alloy produced by high pressure die casting. Journal of Materials Processing Technology, 2007, 189(1-3): 97-106.

[11] Laukli H I, Gourlay C M, Dahle A K. Migration of crystals during the filling of semi-solid castings. Metallurgical and Materials Transactions A, 2005, 36(3): 805-818.

[12] Otarawanna S, Gourlay C M, Laukli H I, et al. Microstructure formation in AISi4MgMn and AIMg5Si2Mn high-pressure die castings. Metallurgical and Materials Transactions A, 2009, 40(7): 1645-1659.

[13] Cao H, Wessén M. Effect of microstructure on mechanical properties of as-cast Mg-Al alloys. Metallurgical \& Materials Transactions A, 2004, 35(1): 309-319.

[14] Wu Mengwu, Xiong Shoumei. Experimental and modeling studies on the structure formation of high pressure die cast magnesium alloy considering the externally solidified crystals in the shot sleeve. Acta Metallurgica Sinica, 2011, 47(5): 528534. (In Chinese)

[15] Wang B S, Xiong S M. Effects of shot speed and biscuit thickness on externally solidified crystals of high-pressure die cast AM60B magnesium alloy. Transactions of Nonferrous Metals Society of China, 2011, 21(4): 767-772.

[16] Li X B, Xiong S M, Guo Z P. On the porosity induced by externally solidified crystals in high-pressure die-cast of AM60B alloy and its effect on crack initiation and propagation. Materials Science \& Engineering A, 2015, 633: 35-41.

[17] Xiao W L, Zhu S M, Easton M A, et al. Microstructural characterization of high pressure die cast Mg-Zn-Al-RE alloys. Materials Characterization, 2012, 65(3): 28-36.

[18] Yang L J, Wei Y H, Hou L F. Microstructure evolution of thixomolding AZ91D magnesium alloy during heat treatment. Journal of Materials Science, 2010, 45(13): 3626-3634.

[19] Laukli H I, Arnberg L, Lohne O. Effects of grain refiner additions on the grain structures in HPDC A356 castings. International Journal of Cast Metals Research, 2005, 18(2): 65-72.

[20] Sequeira W P, Murray M T, Dunlop G L, et al. Effect of section thickness and gate velocity on the microstructure and mechanical properties of high pressure die cast magnesium alloy AZ91D. In: Proceedings of the Symposium on Automotive Alloys, The Minerals, Metals and Materials Society (TMS), Orlando, Florida, 1997: 169-183.

This work was financially supported by the Fundamental Research Funds for the Central Universities (WUT:2017IVA036), 111 Project (B17034) and State Key Laboratory of Materials Processing and Die \& Mould Technology, Huazhong University of Science and Technology (P2018-003). 